\title{
FLUCTUATING ANTENNA MODEL: APPLICATIONS AND PROSPECTS
}

\author{
G. Trinkūnas ${ }^{\mathrm{a}}$ and J. Chmeliov ${ }^{\mathrm{a}, \mathrm{b}}$ \\ a Department of Molecular Compound Physics, Center for Physical Sciences and Technology, Sauletekio 3, 10257 Vilnius, \\ Lithuania \\ ${ }^{\mathrm{b}}$ Institute of Chemical Physics, Faculty of Physics, Vilnius University, Sauletekio 9, 10222 Vilnius, Lithuania \\ Email: gediminas.trinkunas@ftmc.lt
}

Received 11 December 2018; accepted 2 January 2019

\begin{abstract}
Recently, we proposed a simple conceptual fluctuating antenna model (FAM), describing excitation diffusion and trapping in a continuous medium, where variations of the excitation transfer pathways are taken into account by the introduced fractional space dimension. Since then, this model has been successfully applied to simulate multi-exponential excitation quenching kinetics in a series of plant photosynthetic systems, purified from the thylakoid membranes, without invoking a radical pair state in the reaction centre. Here, we overview this model and its parameters obtained for various systems, and extend the area of its applications to several pigment-protein supercomplexes containing the photosystem I (PSI). We show that while the diffusion in the PSI core is virtually three-dimensional, the PSI core aggregates interconnected with other light-harvesting complexes (LHCI and/or LHCII) are characterized by a substantially reduced dimension, which indicates a smaller number of energy transfer links from LHCI to the PSI core. We also suggest that in vivo both PSI and PSII antennae are substantially larger than those observed in the isolated systems: PSII antenna contains in total about 6 LHCII trimers while PSI is aggregated with at least one LHCII trimer. The obtained results show that FAM can be a very useful tool to follow photosynthetic apparatus transformations during short- and long-term adaptation to varying light, monitored by kinetic fluorescence spectroscopy.
\end{abstract} Keywords: time-resolved fluorescence, light harvesting, pigment, photosystem

PACS: 87.15.A-, 31.70.Hq, 71.35.-y, 78.47.D-

\section{Introduction}

Metabolic processes taking place in photosynthetic systems fill the Earth's atmosphere with oxygen and sustain life by converting solar energy into forms accessible to all living organisms. Although during billions years of evolution various photosynthetic organisms have developed different photosynthetic apparatus, the basic principles of their functioning remain the same: at the very heart of the light reactions of photosynthesis lies a huge interconnected network of pigment molecules, usually bound to the protein scaffold. Upon absorption of a photon, the generated electronic excitation is then transferred through this network towards the reaction centre (RC), where its energy is used for charge separation, photolysis of water molecules and creation of the transmembrane electrochemical potential that is utilized during the subsequent stages of photosynthesis [1]. By probing excitation dynamics with optical spectroscopy, one can determine the relation between the structure of the light-harvesting antenna and its function, and, as a result, augment the knowledge on the robustness and efficiency of the photosynthetic apparatus. In this way, by accessing the principles of natural energy production, we can learn how to control them in vivo and/or mimic them in situ. Moreover, understanding of the exact molecular mechanisms responsible for 
the ability to dynamically adapt to varying light conditions, ensuring optimal light harvesting while still avoiding any photodamage [2, 3], opens wide perspectives to increase global crop production by rationally manipulating and controlling the photoprotection yield [ [ 4 ].

The constantly expanding knowledge about the complexity of photosynthetic systems requires introducing new concepts to properly model the primary processes of light harvesting and excitation energy transfer. The internal conformational dynamics of pigment-protein complexes, their ceaseless rearrangement within the thylakoid membrane during state transitions, nonphotochemical quenching (NPQ) and protein repair are key factors responsible for an unsteady structure of photosystems [5]. Few years ago, we proposed a fluctuating antenna model (FAM) to describe the multi-exponential fluorescence decay kinetics observed in the purified photosystem II (PSII) of plants [6]. Traditionally, the non-exponentiality of fluorescence decay has been attributed to the effect of radical pair recombination in the photosynthetic RC. The motivation behind formulating the FAM was the emerging evidence of the irreversibility of charge separation in the RC. On the other hand, we also aimed to take into account the intrinsic dynamic structural and spectral disorder of the light-harvesting antenna. Here we review the latest discoveries done by using FAM, present several applications for photosystem I (PSI) supercomplexes and overview its prospects.

\section{Basics of FAM}

Excitation energy transfer through the light-harvesting antenna is usually described in terms of a coarse-grained model [7-10] by solving the system of Pauli master equations

$$
\frac{\mathrm{d}}{\mathrm{d} t} p_{i}(t)=\sum_{j} k_{j \rightarrow i} p_{j}(t)-\sum_{j} k_{i \rightarrow j} p_{i}(t)
$$

where $p_{i}(t)$ is the time-dependent probability for the excitation to reside on the ith pigment-protein complex or the $i$ th domain of the stronglycoupled pigments, and $k_{i \rightarrow i}$ is the rate of excitation transfer from the $i$ th to the $j$ th complex (or domain). The inter-complex (or inter-domain) excitation transfer rates can be treated as some free parameters [7-9] or can be evaluated from quantum chemistry calculations based on the available structural information [10-14]. This simple approach can successfully describe the relevant timescale of excitation dynamics, but it does not take into account any fluctuations in the antenna structural organization that occur during the time of experimental measurements: however detailed it is, it deals with just a single 'snapshot' of the pigment mutual arrangement. Indeed, from the perspective of excitation random walk through the antenna, broken or weakened transfer links between pigment-protein complexes, molecular clusters or even distinct pigments, as well as differences in the excitation energy of the visited sites form a 'rough' surface for excitation energy diffusion towards the RC. To take into account this 'roughness' as a single parameter, instead of the anisotropic fluctuating links in an integer (1-, 2- or 3-) dimension space, we can consider the isotropic ones in a fractional (lower) dimensional space. By this approach, the apparently unsolvable problem is reformulated into the tractable one, dealing with the excitation diffusion in a spherically symmetric space of the fractional dimension $d(1<d<3)$ with perfect trapping on the boundary surface, resulting in the fluctuating antenna model [6].

Mathematically, FAM is formulated as a continuous diffusion of the initial point-like excitation until it is trapped at some random distance $R$, thus time evolution of the excitation density $p(\vec{r}, t \mid R)$ obeys the following diffusion equation:

$$
\frac{\partial}{\partial t} p(\vec{r}, t \mid R)=D \nabla_{d}^{2} p(\vec{r}, t \mid R)
$$

Here due to the spherical symmetry of excitation migration only the radial part of the $d$-dimensional Laplacian,

$$
\nabla_{d}^{2}=\frac{\partial^{2}}{\partial r^{2}}+\frac{d-1}{r} \frac{\partial}{\partial r}
$$

is relevant, and $D$ is the diffusion constant, related to the average coarse-grained lattice space $(a)$ and hopping time $\left(\tau_{\mathrm{h}}\right)$ constants as $D \simeq a^{2} /\left(2 d \tau_{\mathrm{h}}\right)$ (see Fig. 1). Accordingly, the initial and boundary conditions for Eq. 2 are given as

$$
p(\vec{r}, t=0 \mid R)=\delta(\vec{r}),\left.\quad p(r, t \mid R)\right|_{|\vec{r}|=R}=0,
$$




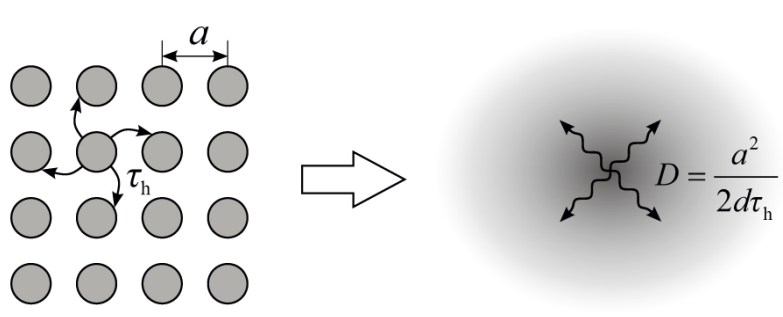

Fig. 1. Switching from the ideal ordered lattice model to the diffusional limit when excitation migration through the antenna is described by a single diffusion equation with the diffusion coefficient $D=a^{2} /\left(2 d \tau_{\mathrm{h}}\right)$, where $a$ is the near-neighbour lattice constant and $\tau_{\mathrm{h}}$ is the corresponding near-neighbour excitation hopping time. Any disturbances in excitation energy transfer at various antenna points are accounted for by introducing the effective noninteger dimensionality $d$.

respectively. By solving Eq. 2 and integrating the obtained excitation density $p(\vec{r}, t \mid R)$ over the whole $d$-dimensional volume

$$
V(R)=\frac{2 \pi^{d / 2}}{d \cdot \Gamma\left(\frac{d}{2}\right)} R^{d},
$$

confined by the spherical boundary of the radius $R$, we obtain the total population of the excitation survived in the system until the time $t$ [6]:

$$
\begin{aligned}
& P(t \mid R)=\int_{V(R)} p(\vec{r}, t \mid R) \mathrm{d} V \\
& =\frac{4}{2^{d / 2} \Gamma\left(\frac{d}{2}\right)} \sum_{n=1}^{\infty} \frac{\left(\xi_{d / 2-1}^{(n)}\right)^{d / 2-2}}{J_{d / 2}\left(\xi_{d / 2-1}^{(n)}\right)} \cdot \mathrm{e}^{-\left(\xi_{d / 2-1}^{(n)} / R\right)^{2} D t} .
\end{aligned}
$$

Here $\Gamma(d / 2)$ stands for the Gamma-function, $J_{d / 2}(\xi)$ is the Bessel function of the first kind and fractional order $d / 2$, while $\xi_{d / 2-1}^{(n)}$ stands for the $n$th zero of the Bessel function $J_{d / 2-1}(\xi)$, obeying $J_{d / 2-1}\left(\xi_{d / 2-1}^{(n)}\right)=0$.

The other important aspect contributing to the complexity of the measured bulk kinetics is related to the dynamic evolution of the antenna organization in time. At normal light conditions, each chlorophyll pigment of the light-harvesting antenna absorbs photons at the average rate of $\sim 10$ photons per second [1], which considerably exceeds the timescale of conformational dynamics of pigment-protein complexes or membrane structural reorganization. Therefore, the pathway for every new excitation (and thus the distance $R$ in the FAM) differs from the former one. The averaging over different pathways of excitation results in a strongly non-exponential kinetics [ 6 ]

$$
\bar{P}(t)=\int_{0}^{\infty} P(t \mid R(V)) c \mathrm{e}^{-c V} \mathrm{~d} V,
$$

where $c$ is the average concentration of the traps. It is worthwhile to mention that the non-exponential behaviour of excitation decay kinetics (Eq. 7) remains even asymptotically when $t \rightarrow \infty$, which is also observed during the experimental timeresolved fluorescence measurements. Indeed, at longer times the infinite series in Eq. 6 is dominated by the single term with the smallest eiger|value $\varepsilon_{1}=D\left(\xi_{d / 2-1}^{(1)} / R\right)^{2}$. By substituting it into Eq. 7 and applying the steepest-descent method to evaluate it at longer times, one can obtain the following asymptotic clearly non-exponential behaviour:

$$
\bar{P}(t) \stackrel{\operatorname{large} t}{=} A_{d}\left(c^{2 / d} D t\right)^{\frac{d}{2 d+4}} \exp \left[-\kappa_{d}\left(c^{2 / d} D t\right)^{\frac{d}{d+2}}\right],
$$

where

$$
\kappa_{d}=\frac{2+d}{d}\left[\frac{\left(\xi_{d / 2-1}^{(1)} \sqrt{\pi}\right)^{d}}{\Gamma\left(\frac{d}{2}\right)}\right]^{\frac{2}{d+2}}
$$

and

$$
A_{d}=\frac{8 \pi^{\frac{d+1}{d+2}}\left(\xi_{d / 2-1}^{(1)}\right)^{\frac{d^{2}-8}{2 d+4}}}{2^{d / 2} \sqrt{2+d} \cdot J_{d / 2}\left(\xi_{d / 2-1}^{(1)}\right) \cdot\left[\Gamma\left(\frac{d}{2}\right)\right]^{\frac{d+3}{d+2}}} .
$$

This asymptotic expression of excitation decay kinetics also reveals that, in fact, our model contains just 2 undetermined parameters: the dimensionality of the system, $d$, and the timescale parameter relating the diffusion coefficient and the mean concentration of the traps, $\eta=\left(D c^{2 / d}\right)^{-1}$, which both can be fitted to the experimentally obtained excitation relaxation kinetics in the light-harvesting antenna. Since the mean concentration of traps is $c \simeq 1 /\left(N a^{d}\right)$, where $N$ is the average number of sites (pigment-protein complexes or molecule domains) per trap, we can relate the timescale parameter $\eta$ to the mean coarse-grained characteristics:

$$
\eta=\left(D c^{2 / d}\right)^{-1} \simeq 2 \mathrm{~d} \tau_{\mathrm{h}} N^{2 / d} .
$$


Interestingly, while the precise expression for the mean excitation kinetics given by Eq. 7 cannot be obtained analytically (the corresponding integral in Eq. 7 should be computed numerically), we can still calculate the resulting mean excitation lifetime

$$
\langle\tau\rangle=\int_{0}^{\infty} P(t) \mathrm{d} t=\frac{\Gamma\left(\frac{2}{d}\right)}{\pi d^{2} D}\left[\frac{\Gamma\left(1+\frac{d}{2}\right)}{c}\right]^{\frac{2}{d}},
$$

or, in terms of the coarse-grained parameters,

$$
\langle\tau\rangle=\tau_{\mathrm{h}} N^{2 / d} \cdot \frac{2 \Gamma\left(\frac{2}{d}\right)}{\pi d}\left[\Gamma\left(1+\frac{d}{2}\right)\right]^{2 / d} .
$$

\section{Recent FAM discoveries}

\subsection{Validation of FAM}

Our proposed FAM was firstly validated by describing non-exponential fluorescence decay kinetics in variously sized PSII supercomplexes [9]. Particularly, we were able to describe the multiexponential kinetics by using only two model parameters (the dimensionality $d$ and the timescale parameter $\eta$ ) without assuming the radical pair equilibration in the RC [6]. Meanwhile, our obtained model parameters (listed in Table 1) were in perfect agreement with the current knowledge on the structural organization of these supercomplexes and excitation dynamics within their light-harvesting antenna. For the PSII core, the obtained dimensionality of $d \approx 1.2$ represents the chain arrangement of the core antenna complexes around the RC, whereas in other PSII preparations (B8-B11 fractions) it gradually increases (up to $d \approx 1.8$ ) with the antenna size, revealing the perturbed coordination within the planar distribution of the pigment-protein complexes. Moreover, from the obtained timescale parameter $\eta$ and Eq. 11 we were able to estimate that the mean inter-complex excitation hopping times in these systems lie within the range of $20-30 \mathrm{ps}$, in agreement with the $\tau_{\mathrm{h}}=25 \mathrm{ps}$ value evaluated for the aggregates of major light-harvesting complexes (LHCII) based on the singlet-singlet annihilation measurements [15] as well as structurebased calculations [10].

\subsection{Recognition of $2 \mathrm{D}$ energy transfer in stacked thylakoid membranes}

The photosynthetic apparatus of plants consists or photosystems of two types, both located in the thylakoid membrane: PSI is mainly present in the unstacked stroma lamellae whereas PSII occupies the stacked thylakoid membranes of grana. In spite of numerous studies, it remained unclear whether under natural conditions the excitation energy migration is planar, i.e. occurs only within the same membrane layer, or takes place across the stacked membrane regions. We have addressed this problem in our recent time-resolved fluorescence study of PSII-enriched grana membranes (BBY), prepared in a stacked and an unstacked form [16]. By applying FAM to the measured fluorescence kinetics, we were able to directly access the information about the dimensionality of the energy transfer process in these systems. We found that both stacked and unstacked membrane preparations exhibited excitation diffusion with the same sub-planar dimension parameter. This supports the view that stacking of the grana lamellae does not affect the efficiency of excitation energy delivery to RCs. Thus it is likely that the membrane stacking merely ensures a more compact organization of thylakoids within the chloroplast as well as proper separation of PSI and PSII [17].

Table 1. FAM parameters, obtained for various light-

\begin{tabular}{|c|c|c|c|c|}
\hline System, conditions & $d$ & $\eta(\mathrm{ns})$ & $\langle\tau\rangle(\mathrm{ps})$ & Ref. \\
\hline PSII core & 1.18 & 0.45 & 76 & {$[6]$} \\
\hline PSII B8 & 1.54 & 0.96 & 104 & {$[6$} \\
\hline PSII B9 & 1.6 & 1.12 & 116 & {$[6]$} \\
\hline PSII B10 & 1.62 & 1.17 & 119 & {$[6$} \\
\hline PSII B11 & 1.78 & 1.6 & 144 & {$[6]$} \\
\hline Stacked BBY & 1.75 & 3.95 & 364 & 16 \\
\hline Unstacked BBY & 1.77 & 3.33 & 303 & {$[16$} \\
\hline LHCII aggregates & 1.7 & 1.3 & 124 & [23] \\
\hline PSI & 2.5 & 1.44 & 92 & {$[3]$} \\
\hline PSII, open RC, dark & 1.9 & 3.89 & 286 & {$[3]$} \\
\hline PSII, open RC, NPQ & 1.9 & 2.53 & 194 & {$[3]$} \\
\hline $\begin{array}{c}\text { PSII, closed RC, } \\
\text { NPQ }\end{array}$ & 1.9 & 3.27 & 240 & [3] \\
\hline
\end{tabular}
harvesting systems. 


\subsection{Planar organization of LHCII aggregates}

One of the most remarkable features of oxygenic photosynthesis is self-regulation of sunlight energy flow in a cell avoiding photodamage by dangerous reactive products caused by an overexcited light-harvesting antenna. The excess excitation energy is dissipated to heat during non-photochemical quenching. Although several models have been suggested to govern NPQ on a molecular level [18-22] and the final consensus has been still not reached, it is believed that it takes place mostly in LHCII complexes, as monitored by a significant drop of fluorescence intensity in LHCII aggregates compared to non-aggregated species. To get insight into the physical origin of NPQ, a thorough study of LHCII trimers and aggregates has been performed recently over a wide temperature range [23]. By analysing the measured highresolution time-resolved fluorescence spectra, the relevant quenching states and their conformational nature have been identified. The application of FAM to describe the multi-exponential fluorescence decay kinetics data at physiological temperatures revealed the dimensionality parameter $d=1.7$, again indicating the planar excitation diffusion at the presence of some disorder in connectivity between the pigment-protein complexes within the aggregate. This result is very close to our earlier estimates of $d=1.9$ [24] for the LHCII aggregates formed from the npq1 mutant [25]. The obtained time scale parameter $\eta=1.3 \mathrm{~ns}$, combined with the excitation hopping time $\tau_{\mathrm{h}}=25 \mathrm{ps}$ between the LHCII monomers [15], gives the estimate for the concentration of the NPQ-traps, $N_{\text {trap }}=10 \%$, which is very close to the results obtained from the coarse-grained model [23].

\subsection{Probing short term NPQ in leaves}

Recently, we have also studied the short-term adaptability of the photosynthetic thylakoid membranes of plants in response to a continuous intense illumination by measuring their time-resolved fluorescence spectra under conditions of either open or closed RCs [3]. We have discovered a new feature of NPQ in plants: while several different quenching mechanisms coexist, one of them is only functional when the PSII reaction centres are closed, while being absent when RCs are open. This finding is of great importance as it emphasizes the economic nature of NPQ [2] that is physiologically needed only when RCs are closed and overexcitation can lead to formation of dangerous radicals. In contrast to the commonly assumed independence of NPQ on the RC oxidative state, we have unambiguously demonstrated that the rate of NPQ is lower in the case of open RCs, which leads to increased efficiency of photosynthesis in light-stress conditions. To distinguish between the PSII and PSI contributions to the measured fluorescence from the leaves, we applied the self-modelling curve resolution approach, thus extracting 'raw' transient spectra of both photosystems [3]. Again, FAM was able to perfectly reproduce the multi-exponential decay behaviour of the extracted kinetics. The obtained FAM parameters are presented in Table 1. It can be noticed that the fractional dimensionalities of both photosystems ( $d \approx 2.5$ and 1.9 for PSI and PSII, respectively) did not change with short-term acclimation to high-light conditions. The timescale parameter $\eta$, remaining the same for PSI and varying for PSII, reflects the generation of NPQ-traps in PSII only.

From comparing the PSII B11 fractions, containing 11 antenna pigment-protein complexes per RC, with the PSII from the unstacked BBY membrane preparation, we see that the dimensionalities of both systems are very close (see Table 1). On the other hand, the timescale parameters $\eta$ for these two systems differ more than twofold. By using Eq. 11 and $d=1.78$, we can estimate that BBY membranes should contain $\sim 11$ extra complexes compared to the B11 supercomplexes, which corresponds to $\sim 4$ additional LHCII trimers. Taking into account that parameters of dark-adopted PSII (with open RCs) in leaves have values close to those of BBY preparations, we can conclude that the in vivo PSII could be substantially larger and contain in total around 6 LHCII trimers per RC.

\section{Extending the area of FAM application to PSI supercomplexes}

\subsection{Traditional modelling}

It is well-known that quantum efficiency of PSI is extremely high: up to $99 \%$ of the photoinduced excitation is successfully utilized in the PSI RCs [1]]. In fact, the mean excitation lifetime in PSI is 
several times shorter than that in PSII. The intrinsic charge separation in RC of PSI is even faster than in PSII [26] and is irreversible [27]. In the PSI core, the mean excitation lifetime is about just 2040 ps [28]. Usually, the PSI excitation kinetics is measured by time-resolved techniques - transient absorption, fluorescence up-conversion, streakcamera or time-correlated single photon counting, - while the collected data is then processed by a global analysis approach [29]. Therefore, the PSI kinetics is represented in series of exponentially decaying components with wavelengthdependent amplitudes. The final target-oriented modelling results in the compartments with species spectra and inter-species communication rate constants. However, this approach can hardly be useful to interpret excitation dynamics in terms of the revealed variability of energy transfer pathways [30] or the evidences for inter-conversions of the light-harvesting complexes Lhca (PSI) and Lhcb (PSII) [31]. The latter effect very closely resembles the dynamic disorder, well known for PSII antenna complexes [32].

Table 2. FAM parameters for PSI samples of various size.

\begin{tabular}{|c|c|c|c|c|}
\hline System, conditions & $d$ & $\eta$ (ns) & $\langle\tau\rangle(\mathrm{ps})$ & Ref. \\
\hline PSI core & 2.49 & 0.32 & 21.2 & [36] \\
\hline PSI-Lhca1-4 & 1.8 & 0.47 & 46.5 & {$[36$} \\
\hline PSI-Lhca $5^{*}$ & 1.97 & 0.56 & 51.3 & [36] \\
\hline PSI WT & 1.78 & 0.59 & 52.9 & [36] \\
\hline PSI & 1.97 & 0.83 & 66 & [37] \\
\hline PSI-LHCII & 2.1 & 0.99 & 74 & [37] \\
\hline PSI-LHCI & 1.86 & 0.42 & 35.6 & {$[38]$} \\
\hline
\end{tabular}

* It is a type of PSI-WT with Lhca4 replaced by Lhca5, missing a red form. WT stands for the wild-type samples.

\subsection{Introducing $F A M$}

The aforementioned description of the in vivo PSI fluorescence kinetics in terms of FAM [3] encourages application of FAM to the isolated PSI complexes as well. Since the PSI antenna is obviously distinct from that of PSII, extra arguments prior to FAM application are in order. The core of PSI is composed of up to 16 subunits [33], accounting for about half of total antenna chlorophylls, almost homogeneously distributed in space around the RC site. However, in spite of the random orientation of their transition dipoles, excitonic coupling groups them into several clusters of a longer excitation residence [34, 35]. Taking into account that the remaining half of the antenna chlorophylls are bound to four light-harvesting complexes LHCI, the coarse-grained view of energy transfer in the fluctuating PSII antenna emerges for PSI as well.

\subsection{PSI core, PSI core-LHCI}

In order to validate FAM for the isolated plant PSI, we analysed the published fluorescence kinetics data of series of supercomplexes in ascending sizes, from PSI core complexes to PSI-LHCI (or LHCII) supercomplexes [36, 37]. All the kinetics present series of exponentially decaying components with corresponding decay-associated spectra that we integrated to get the amplitudes of exponentials. From all the experimental data, we chose the subsets corresponding to the homogeneous excitation conditions, closely following the initial conditions most appropriate to FAM.

The former study [36] aimed to develop the role of the 'red' pigments in energy transfer and trapping by starting from the isolated PSI core as well as dimeric complexes Lhca2/3, Lhca1/4 and Lhca5, and increasing the complexity of the resulting system by gradually reconstituting into the whole PSI supercomplex. This series is indeed very useful for our purpose because we can follow the effect of the attached complexes with (Lhc4) and without the red forms (Lhc5) independently. As expected, the experimental kinetics (see Table 1 in [36]) can be reasonably well described by our FAM (see Fig. 2 and Table 2 for the corresponding fits and the obtained model parameters). First, the timescale parameter $\eta$ very well correlates with the antenna size. Somehow unexpectedly, the fractional dimensionality of the PSI core results in the largest number, indicating a very good site coordination or connectivity for the energy transfer. It coincides with the same parameter obtained for the in vivo PSI in leaves (see Table 1). Attaching Lhca complexes on the one side of the core naturally decreases the coordination (compare the dimensions of the PSI core and PSI-WT samples). By comparing the dimensionalities of PSI-WT and PSI-Lhca5 (the latter being homologous to 


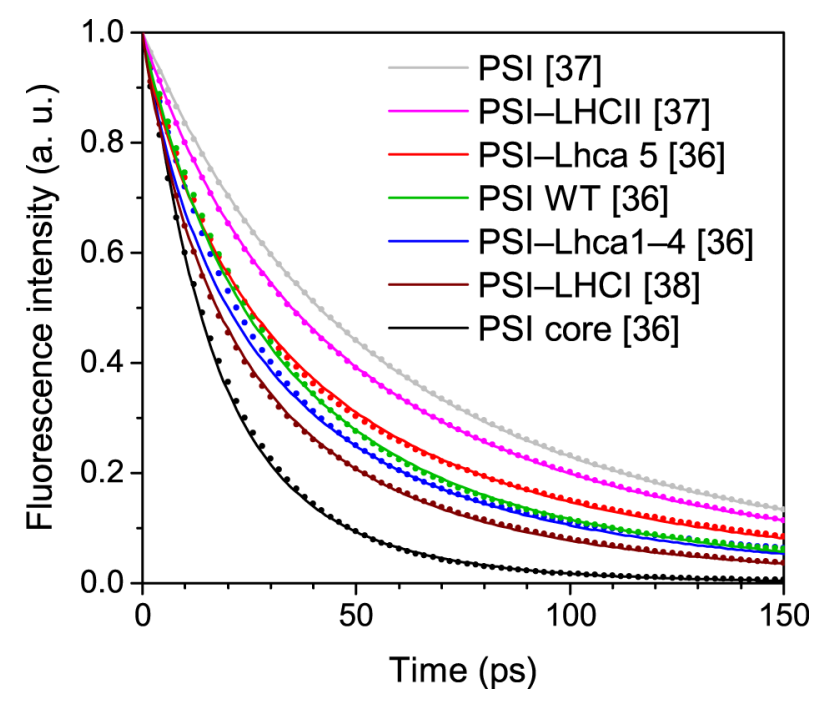

Fig. 2. Experimental [36-38] (dots) and simulated (lines) fluorescence decay kinetics in various PSI samples. The simulated curves were calculated using the fitted parameters of FAM presented in Table 2. The PSI samples in the legend are listed in the order of the kinetics decay rate: PSI corresponds to the slowest kinetics and the PSI core to the fastest one.

PSI-WT except for the Lhca4 with the red pigments being replaced by Lhca5 without them), we see that the red pigments reduce the coordination of visited sites.

\subsection{PSI core-LHCI-LHCII}

In the study on Arabidopsis thaliana wild type plants [37] it has been discovered that, in contrast to the previous general belief, under a wide range of light intensities, including sunlight, LHCII is associated with PSI. LHCII dissociates from PSI only in shade-light or sudden high-light conditions. In Table 2 we also present the FAM parameters obtained by fitting the fluorescence kinetic data of the isolated PSI and PSI-LHCII supercomplexes (see Fig. 4 in [37]). First, the timescale parameters $\eta$ of both systems indicate that these preparations contain larger and better-coordinated antennae. The increased and relatively high dimensionality of PSI-LHCII indicates a better connectivity between PSI and LHCII compared to that of Lhcas, in agreement with the conclusion of the original study [ 37 . This encourages us to make a guess that in the acclimated leaves [3] the PSI supercomplex might contain even more LHCII complexes since the obtained PSI dimen- sionality $d$ and the timescale parameter $\eta$ are considerably higher.

\subsection{Number of sites in the PSI antenna}

The excitation anisotropy measurements in the PSI-WT supercomplexes from the spinach [39] reported the anisotropy decay time within the 5-13 ps range, depending on the excitation wavelength. These numbers can serve as the estimates of upper limits to the excitation hopping time. Using these values as well as $\eta=0.59 \mathrm{~ns}$ from Table 2 for PSI-WT, we can estimate the number of sites relevant for the excitation transfer through the antenna

$$
N=\left(\frac{\eta}{2 d \tau_{\mathrm{h}}}\right)^{2 / d},
$$

which gives the following upper limit of the number of sites: $10<N^{\text {upper }}<22$. The former value (10) surprisingly well corresponds to the locations of the 6 lowest excitonic states in the limits of thermal energy $k_{\mathrm{B}} T$, defined by genetic algorithm search of the steady state spectra of the PSI core [34] and 4 additional sites corresponding to the Lhca1/4 and Lhca2/3 complexes.

\subsection{Radical pair-antenna excitation equilibration in PSI}

It is well established that excitation trapping in the $\mathrm{RC}$ is very fast and irreversible, irrespective of the $\mathrm{RC}$ redox state [40]. In spite of this evidence, there were some earlier [41] and quite recent [37] attempts to assert the radical pair (RP) and antenna exciton equilibration, or the trapping-limited view of excitation dynamics in PSI. The main cause for that is the apparent multi-exponentiality of excitation decay kinetics, which can be easily simulated by including the RP recombination. In this limiting case, the trapping time is approximately equal to the excitation mean lifetime and can be described by a simple expression [42]

$$
\tau_{\text {trap }}=N_{\text {eff }}\left[\tau_{\mathrm{CS}}+\tau_{\mathrm{RP}} \exp \left(-\frac{\Delta G}{k_{\mathrm{B}} T}\right)\right],
$$

where $N_{\text {eff }}$ is the effective number of pigments/ complexes, $\tau_{\mathrm{CS}}$ is the primary charge separation 
time in $\mathrm{RC}, \tau_{\mathrm{RP}}$ is the RP relaxation time and $\Delta G$ is the drop in free energy upon formation of RP. However, the Arrhenius plot of the temperature dependence of the fluorescence yield measured, e.g. for the PSI of maize, has an acute angle (see Fig. 4 in [43]), in contrast to the obtuse one following from Eq. 15. This contradiction, added to the arguments discussed above, totally eliminates the idea of the trap-limited description of excitation transfer. To further support the migration-limited character of the excitation decay in PSI, once again we apply FAM to simulate the recent fluorescence decay data of PSI supercomplexes isolated from the spinach thylakoids [38]. The two-parameter fitting of the experimental data shown in Fig. 2 is impeccable indeed. The obtained parameters, presented in Table 2, are also in a good agreement with those obtained for the correspondingly sized PSIWT [36] and PSI [37] supercomplexes.

To summarize, the presented simulations of the excitation decay kinetics in PSI particles and the comparison of FAM parameters listed in Table 2 suggest that PSI in leaves [3] is a much larger supercomplex and can be composed of the PSI core, LHCI and few extra LHCII trimers, as suggested in [37].

\section{Discussion: conclusions and prospects of the model}

\subsection{Demand for the supramodelling tools}

Photosynthetic systems show complex relations between the structure and function. Much effort has been put in the past to disintegrate thylakoid membranes and to study part-by-part pigment-protein complexes with the aim to find out the states responsible for the robustness and unprecedented efficiency of photoconversion. Nowadays, when more and more studies appear focused on the organization and behaviour of the integral thylakoid membranes or even total cells of physiological relevance, the demand for appropriate supramodelling tools emerges.

The way of combining the knowledge of separate pigment-protein models into the whole supercomplex picture is not trivial. At the time of introduction of a coarse-grained model of excitation energy transfer and trapping in PSII based on electron microscopy images [⿰], many models of radical pair formation in isolated RCs were proposed. However, none of the four most popular models from three different laboratories [44-47] used in combination with the coarse-grained modelling approach was able to simulate fluorescence decay of PSII including BBY preparations [7, 48]. Prior to this attempt, it was already noticed that the obtained charge separation parameters even in D1D2-cyt and PSII-core complexes differ significantly [44].

\subsection{Parameter-less modelling}

On a much larger scale, the strategy of combining the latest detailed theoretical models, based on the Förster/modified Redfield approach of smaller systems [10], has been recently successfully performed by parameter-less simulations of large areas of thylakoid membranes [49, 50]. However, the radical pair state of PSII RC explicitly taken into account again casts doubts about the inability to simulate multi-exponential kinetics without including a radical pair recombination. Indeed, by raising the problem that quality of the fitted fluorescence kinetics is not a proxy for accuracy of energy transfer models, Bennett et al. [10] (see Table 3 therein) provide the evidence that four models of PSII particles B8-11 using different charge separation parameters equally well describe the measured kinetics. Beside this important note, one more surprising feature can be seen: all the models under scope in general are of a coarse-grained type and differ only in the size of the elementary units participating in the excitation transfer. One limiting case is the excitation radical-pair equilibration (ERPE) model [47, which contains only five compartments. The other limiting case is the molecular domain model [10] with a large number of clusters of strongly-coupled pigments. These models are also characterized by the values of free energy of the RP state, which is the smallest for ERPE and the largest for the domain model. The other two models - protein [7] and transfer-to-trap-limiting ones [51] - are well interpolating between the mentioned limiting cases. The smallest free energy gap defines the dominating $\mathrm{RP}$ recombination role in kinetics. Meanwhile, the spectral and spatial inhomogeneity of pigment clusters provides a major contribution to the non-exponential excitation decay in 
the domain model and therefore the RP state with the largest free energy adds very little to the RP recombination. Nevertheless, it is a common feature of all these models that the structures of PSII used in simulations are the static 'snapshots' of the dynamically varying photosynthetic units.

In contrast, FAM uncovers all the potential of possibilities using a very limited number of parameters to follow the dynamic processes of natural light energy conversion and adaptation. While the experimental kinetics of membrane or cell data contain four to five exponential lifetimes, the FAM has proven to be a simple two-parameter model, suitable not only to properly describe excitation dynamics in both photosystems, aggregates of light-harvesting complexes or even thylakoid membranes, but also to extract some structural information about these systems. FAM can be invaluable in simulating the evolution of the photosynthetic apparatus during the short-term adaptation including state transitions when aggregated or separate LHCII complexes travel between PSII and PSI, as well as in long-term reorganizations to recognise changes in the stoichiometry of PSI and PSII.

\section{References}

[1] R.E. Blankenship, Molecular Mechanisms of Photosynthesis, 2nd ed. (Wiley Blackwell, Chichester, 2014).

[2] E. Belgio, E. Kapitonova, J. Chmeliov, C.D.P. Duffy, P. Ungerer, L. Valkunas, and A.V. Ruban, Economic photoprotection in photosystem II that retains a complete light-harvesting system with slow energy traps, Nat. Commun. 5, 4433 (2014).

[3] S. Farooq, J. Chmeliov, E. Wientjes, R. Koehorst, A. Bader, L. Valkunas, G. Trinkunas, and H. van Amerongen, Dynamic feedback of the photosystem II reaction centre on photoprotection in plants, Nat. Plants 4(4), 225-231 (2018).

[4] J. Kromdijk, K. Głowacka, L. Leonelli, S.T. Gabilly, M. Iwai, K.K. Niyogi, and S.P. Long, Improving photosynthesis and crop productivity by accelerating recovery from photoprotection, Science 354, 857-861 (2016).

[5] C.D.P. Duffy, L. Valkunas, and A.V. Ruban, Lightharvesting processes in the dynamic photosyn- thetic antenna, Phys. Chem. Chem. Phys. 15(43), 18752-18770 (2013).

[6] J. Chmeliov, G. Trinkunas, H. van Amerongen, and L. Valkunas, Light harvesting in a fluctuating antenna, J. Am. Chem. Soc. 136(25), 8963-8972 (2014).

[7] K. Broess, G. Trinkunas, C.D. van der Weij-de Wit, J.P. Dekker, A. van Hoek, and H. van Amerongen, Excitation energy transfer and charge separation in photosystem II membranes revisited, Biophys. J. 91(10), 3776-3786 (2006).

[8] L. Valkunas, G. Trinkunas, J. Chmeliov, and A.V. Ruban, Modeling of exciton quenching in photosystem II, Phys. Chem. Chem. Phys. 11(35), 7576-7584 (2009).

[9] S. Caffarri, K. Broess, R. Croce, and H. van Amerongen, Excitation energy transfer and trapping in higher plant photosystem II complexes with different antenna sizes, Biophys. J. 100(9), 20942103 (2011).

[10]D.I.G. Bennett, K. Amarnath, and G.R. Fleming, A structure-based model of energy transfer reveals the principles of light harvesting in photosystem II supercomplexes, J. Am. Chem. Soc. 135(24), 9164-9173 (2013).

[11]V.I. Novoderezhkin, M.A. Palacios, H. van Amerongen, and R. van Grondelle, Excitation dynamics in the LHCII complex of higher plants: Modeling based on the $2.72 \AA$ crystal structure, J. Phys. Chem. B 109(20), 10493-10504 (2005).

[12]F. Müh, T. Renger, and A. Zouni, Crystal structure of cyanobacterial photosystem II at $3.0 \AA$ resolution: A closer look at the antenna system and the small membrane-intrinsic subunits, Plant Physiol. Biochem. 46(3), 238-264 (2008).

[13]C.D.P. Duffy, L. Valkunas, and A.V. Ruban, Quantum mechanical calculations of xanthophyll-chlorophyll electronic coupling in the lightharvesting antenna of photosystem I of higher plants, J. Phys. Chem. B 117(25), 7605-7614 (2013).

[14]J. Chmeliov, W.P. Bricker, C. Lo, E. Jouin, L. Valkunas, A.V. Ruban, and C.D.P. Duffy, An 'all pigment' model of excitation quenching in LHCII, Phys. Chem. Chem. Phys. 17(24), 15857-15867 (2015). 
[15]V. Barzda, V. Gulbinas, R. Kananavicius, V. Cervinskas, H. van Amerongen, R. van Grondelle, and L. Valkunas, Singlet-singlet annihilation kinetics in aggregates and trimers of LHCII, Biophys. J. 80(5), 2409-2421 (2001).

[16]S. Farooq, J. Chmeliov, G. Trinkunas, L. Valkunas, and $\mathrm{H}$. van Amerongen, Is there excitation energy transfer between different layers of stacked photosystem-II-containing thylakoid membranes? J. Phys. Chem. Lett. 7(7), 1406-1410 (2016).

[17]G. Garab, Self-assembly and structural-functional flexibility of oxygenic photosynthetic machineries: Personal perspectives, Photosynth. Res. 127, 131-150 (2016).

[18]N.E. Holt, D. Zigmantas, L. Valkunas, X.P. Li, K.K. Niyogi, and G.R. Fleming, Carotenoid cation formation and the regulation of photosynthetic light harvesting, Science 307(5708), 433-436 (2005).

[19]A.A. Pascal, Z.F. Liu, K. Broess, B. van Oort, H. van Amerongen, C. Wang, P. Horton, B. Robert, W.R. Chang, and A. Ruban, Molecular basis of photoprotection and control of photosynthetic light-harvesting, Nature 436(7047), 134-137 (2005).

[20]A.V. Ruban, R. Berera, C. Ilioaia, I.H.M. van Stokkum, J.T.M. Kennis, A.A. Pascal, H. van Amerongen, B. Robert, P. Horton, and R. van Grondelle, Identification of a mechanism of photoprotective energy dissipation in higher plants, Nature 450(7169), 575-578 (2007).

[21]T.K. Ahn, T.J. Avenson, M. Ballottari, Y.C. Cheng, K.K. Niyogi, R. Bassi, and G.R. Fleming, Architecture of a charge-transfer state regulating light harvesting in a plant antenna protein, Science 320(5877), 794-797 (2008).

[22]H. Staleva, J. Komenda, M.K. Shukla, V. Šlouf, R. Kaňa, T. Polívka, and R. Sobotka, Mechanism of photoprotection in the cyanobacterial ancestor of plant antenna proteins, Nat. Chem. Biol. 11(4), 287-291 (2015).

[23]J. Chmeliov, A. Gelzinis, E. Songaila, R. Augulis, C.D.P. Duffy, A.V. Ruban, and L. Valkunas, The nature of self-regulation in photosynthetic lightharvesting antenna, Nat. Plants 2, 16045 (2016).
[24]J. Chmeliov, G. Trinkunas, H. van Amerongen, and L. Valkunas, Excitation migration in fluctuating light-harvesting antenna systems, Photosynth. Res. 127(1), 49-60 (2016).

[25]M.G. Müller, P. Lambrev, M. Reus, E. Wientjes, R. Croce, and A.R. Holzwarth, Singlet energy dissipation in the photosystem II light-harvesting complex does not involve energy transfer to carotenoids, ChemPhysChem 11(6), 1289-1296 (2010).

[26]M. Mamedov, G.V. Nadtochenko, and A. Semenov, Primary electron transfer processes in photosynthetic reaction centers from oxygenic organisms, Photosynth. Res. 125, 51-63 (2015).

[27]D.A. Cherepanov, G.E. Milanovsky, O.A. Gopta, R. Balasubramanian, D.A. Bryant, A.Y. Semenov, and J.H. Golbeck, Electron-phonon coupling in cyanobacterial photosystem I, J. Phys. Chem. B 122, 7943-7955 (2018).

[28]R. Croce and H. van Amerongen, Light-harvesting in photosystem I, Photosynth. Res. 116(2-3), 153-166 (2013).

[29]I.H.M. van Stokkum, D.S. Larsen, and R. van Grondelle, Global and target analysis of timeresolved spectra, Biochim. Biophys. Acta 1657, 82-104 (2004).

[30]M. Brecht, V. Radics, J.B. Nieder, and R. Bittl, Protein dynamics-induced variation of excitation energy transfer pathways, Proc. Natl. Acad. Sci. U.S.A. 106(29), 11857-11861 (2009).

[31]T.P.J. Krüger, E. Wientjes, R. Croce, and R. van Grondelle, Conformational switching explains the intrinsic multifunctionality of plant light-harvesting complexes, Proc. Natl. Acad. Sci. U.S.A. 108(33), 13516-13521 (2011).

[32]T.P.J. Krüger, V.I. Novoderezkhin, C. Ilioaia, and R. van Grondelle, Fluorescence spectral dynamics of single LHCII trimers, Biophys. J. 98(12), 3093-3101 (2010).

[33]I. Caspy and N. Nelson, Structure of the plant photosystem I, Biochem. Soc. Trans. 46, 285-294 (2018).

[34]S. Vaitekonis, G. Trinkunas, and L. Valkunas, Red chlorophylls in the exciton model of photosystem I, Photosynth. Res. 86, 185-201 (2005). 
[35]M.K. Sener, C. Jolley, A. Ben-Shem, P. Fromme, N. Nelson, R. Croce, and K. Schulten, Comparison of the light-harvesting networks of plant and cyanobacterial photosystem I, Biophys. J. 89, 16301642 (2005).

[36]E. Wientjes, I.H.M. van Stokkum, H. van Amerongen, and R. Croce, The role of the individual Lhcas in photosystem I excitation energy trapping, Biophys. J. 101(3), 745-754 (2011).

[37]E. Wientjes, H. van Amerongen, and R. Croce, LHCII is an antenna of both photosystems after long-term acclimation, Biochim. Biophys. Acta Bioenerg. 1827(3), 420-426 (2013).

[38]E. Molotokaite, W. Remelli, A.P. Casazza, G. Zucchelli, D. Polli, G. Cerullo, and S. Santabarbara, Trapping dynamics in photosystem I-light harvesting complex I of higher plants is governed by the competition between excited state diffusion from low energy states and photochemical charge separation, J. Phys. Chem. B 121, 9816-9830 (2017).

[39] T.P. Causgrove, S. Yang, and W.S. Struve, Polarized pump-probe spectroscopy of photosystem I antenna excitation transport, J. Phys. Chem. 93(18), 6844-6850 (1989).

[40]S. Savikhin, W. Xu, P.R. Chitnis, and W.S. Struve, Ultrafast primary processes in PSI from Synechocystis sp. PCC 6803: Roles of P700 and A(0), Biophys. J. 79, 1573-1586 (2000).

[41]C. Slavov, M. Ballottari, T. Morosinotto, R. Bassi, and A.R. Holzwarth, Trap-limited charge separation kinetics in higher plant photosystem I complexes, Biophys. J. 94, 3601-3612 (2008).

[42]B. van Oort, M. Alberts, S. de Bianchi, L. Dall'Osto, R. Bassi, G. Trinkunas, R. Croce, and H. van Amerongen, Effect of antenna-depletion in photosystem II on excitation energy transfer in Arabidopsis thaliana, Biophys. J. 98(5), 922-931 (2010).

[43]R.C. Jennings, G. Zucchelli, R. Croce, and F.M. Garlaschi, The photochemical trapping rate from red spectral states in PSI-LHCI is determined by thermal activation of energy transfer to bulk chlorophylls, Biochim. Biophys. Acta Bioenerg. 1557, 91-98 (2003).
[44]S. Vassiliev, C.-I. Lee, G.W. Brudvig, and D. Bruce, Structure-based kinetic modeling of excited-state transfer and trapping in histidine-tagged photosystem II core complexes from Synechocystis, Biochemistry 41(40), 12236-12243 (2002).

[45]E.G. Andrizhiyevskaya, D. Frolov, R. van Grondelle, and J.P. Dekker, On the role of the CP47 core antenna in the energy transfer and trapping dynamics of photosystem II, Phys. Chem. Chem. Phys. 6(20), 4810-4819 (2004).

[46]M.L. Groot, N.P. Pawlowicz, L.J.G.W. van Wilderen, J. Breton, I.H.M. van Stokkum, and R. van Grondelle, Initial electron donor and acceptor in isolated Photosystem II reaction centers identified with femtosecond mid-IR spectroscopy, Proc. Natl. Acad. Sci. U.S.A. 102(37), 1308713092 (2005).

[47]Y. Miloslavina, M. Szczepaniak, M.G. Müller, J. Sander, M. Nowaczyk, M. Rögner, and A.R. Holzwarth, Charge separation kinetics in intact photosystem II core particles is trap-limited. A picosecond fluorescence study, Biochemistry 45(7), 2436-2442 (2006).

[48]K. Broess, G. Trinkunas, A. van Hoek, R. Croce, and $H$. van Amerongen, Determination of the excitation migration time in photosystem II - consequences for the membrane organization and charge separation parameters, Biochim. Biophys. Acta Bioenerg. 1777(5), 404-409 (2008).

[49]K. Amarnath, D.I.G. Bennett, A.R. Schneider, and G.R. Fleming, Multiscale model of light harvesting by photosystem II in plants, Proc. Natl. Acad. Sci. U.S.A. 113, 1156-1161 (2016).

[50]D.I.G. Bennett, G.R. Fleming, and K. Amarnath, Energy-dependent quenching adjusts the excitation diffusion length to regulate photosynthetic light harvesting, Proc. Natl. Acad. Sci. U.S.A. 115, E9523-E9531 (2018).

[51]C.D. van der Weij-de Wit, J.P. Dekker, R. van Grondelle, and I.H.M. van Stokkum, Charge separation is virtually irreversible in photosystem II core complexes with oxidized primary quinone acceptor, J. Phys. Chem. A 115(16), 3947-3956 (2011). 
FLIUKTUOJANČIOSIOS ANTENOS MODELIS: TAIKYMAI IR PERSPEKTYVOS

\author{
G. Trinkūnas ${ }^{\mathrm{a}}$, J. Chmeliov ${ }^{\mathrm{a}, \mathrm{b}}$ \\ ${ }^{a}$ Fiziniu ir technologijos mokslu centro Molekuliniu dariniu fizikos skyrius, Vilnius, Lietuva \\ ${ }^{\mathrm{b}}$ Vilniaus universiteto Fizikos fakultetas, Vilnius, Lietuva
}

\section{Santrauka}

Neseniai buvo pasiūlytas paprastas konceptualus fliuktuojančiosios antenos modelis (FAM), apibūdinantis sužadinimo difuziją ir pagavimą tolydžioje terpèje bei atsižvelgiantis ị kintančius sužadinimo pernašos kelius trupmenine erdvès dimensija. Nuo FAM paskelbimo jis buvo sèkmingai pritaikytas modeliuojant neeksponentines sužadinimo gesimo kinetikas daugelyje augalų fotosintetinių sistemų neịvedant radikalų poros būsenų reakcijų centruose. Apžvelgiami gauti sistemų parametrai ir praplečiamos FAM taikymo sritys iqvairioms pirmosios fotosistemos (PSI) dalelèms, kaip, pavyzdžiui, PSI kompleksui su pagrindiniu augalų šviesorankos kompleksu LHCII.
Parodoma, kad sužadinimo difuzija PSI branduolio komplekse yra beveik trimatè. PSI branduolio ir LHCI superkompleksui būdinga daug mažesnè dimensija, atspindinti minimalų energijos pernašos jungčių skaičių tarp LHCI ir PSI branduolio. FAM ịvertinimai rodo, kad tiek PSI, tiek PSII antenos natūraliomis sąlygomis yra daug didesnès nei žinomose sistemose, ištrauktose iš tilakoidų membranų: PSII antenoje yra maždaug 6 LHCII trimerai, o PSI yra agreguota su bent vienu LHCII trimeru. Rezultatai rodo, kad remiantis kinetinès fluorescencijos spektroskopijos duomenimis, FAM gali būti labai naudingas siekiant stebèti fotosintetinių sistemų kaitą tiek trumpalaikiame, tiek ir ilgalaikiame prisitaikyme prie kintančios apšvitos. 